\title{
Swell and Consolidation Characteristics of Fiber Reinforced Cohesive Soil
}

\author{
I. Rajeena ${ }^{1}$ and S. P. Jeyapriya ${ }^{2}$ \\ ${ }^{1}$ PG Student, ${ }^{2}$ Assistant Professor, \\ Department of Civil Engineering, Government College of Technology, Coimbatore, Tamil Nadu, India \\ E-Mail:rajeerosh@gmail.com, jeyapriyagct@yahoo.com
}

\begin{abstract}
Naturally occurring expansive clays show detrimental changes in volume when subjected to variation in water content. It leads to significant damages in foundations that are seated on these materials used for the construction in pavement, bridges especially in light weight buildings. The improvement could be in terms of reducing the swelling and differential settlement or increasing the shear strength of clayey soil. Reinforcing soil using fiber is one of the ground improvement techniques in which fibers are mixed randomly with the soil, in similar fashion to mixing with lime, cement or other additives. It eliminates the potential weak planes and maintains the strength isotropy by random reinforcement. The main objective of this study is to investigate the effect of synthetic polypropylene fibers on the swelling and consolidation characteristics of clay soil. The parameters considered for the study include the swelling pressure, swell potential and consolidation characteristics. Polypropylene fiber with aspect ratio $(1 / d) 12$ is varied at $0 \%, 0.1 \%, 0.25 \%$, $0.50 \%$ and $0.75 \%$ by dry weight of the soil is used as reinforcement. The swell potential(S\%) and the swelling pressure(P) decreased with the addition of fiber. From the experimental results, $0.5 \%$ of polypropylene fiber is considered to be optimum. The results also revealed that the rate of heave formation is very less compared to that of unreinforced soil. From the consolidation test, it was observed that compression index, co efficient of compressibility and co efficient of volume change are $0.22,0.8 \mathrm{~mm}^{2} / \mathrm{N}$ and $0.48 \mathrm{~mm}^{2} / \mathrm{N}$ at the optimum fiber percentage.

Keywords: Aspect ratio, Expansive soil, Ground improvement technique, Polypropylene fiber, Swell and consolidation, Volume change
\end{abstract}

\section{INTRODUCTION}

Cohesive soil poses numerous problems to Civil Engineers because of volumetric changes and poor shear strength. Due to its high compressibility, the structures on this material experience downward movement or settlement. The one dimensional consolidometer is widely used for the measurement of swell and consolidation characteristics of expansive soil [4][12]. The process of soil reinforcement helps to achieve the required properties of soil. It eliminates the effect of swelling [7] and substantially reduces the consolidation settlement [6], the concept of which was first given by Vidal. Desirable properties in cohesive soil are achieved by mechanical, chemical and physical method. Mechanical methods are conducted by compaction and consolidation. In chemical method, in order to improve its engineering properties some additives are added into the soil [8] [14]. Whereas in physical method the soil is subjected to alternative wetting and drying. The random reinforcement technique eliminate potential weak plane and maintain strength isotropy [5].

The Coefficient of consolidation increases with increase in percentage addition of fiber that means time required to attain primary consolidation is very less compared to that of unreinforced soil [11]. Fiber inclusion in expansive soil decreased the swell potential and swelling pressure [9]. As the fiber content increases in the soil,the unconfined compressive strength, stiffness and ductility also increases [2]. Previous studies states that the compressibility and coefficient of volume change for reinforced clay is lesser than the untreated clay [10].There is reduction in heave and swelling pressure accordingly with addition of different aspect ratios of Polypropylene fiber [13]. Lower aspect ratio has greater effect in reducing swelling pressure [1]. The soil tensile strength can be significantly enhanced with the small dosage of fiber inclusion [3].

This paper presents the results of the oedometer test performed on fiber reinforced and unreinforced soil. Swell potential, swelling pressure, compression index, coefficient of compressibility, coefficient of volume change has been determined. The main objective of the work is to control the volumetric changes of clay soil and to find the optimum fiber content which improves swell and consolidation characteristics of clay soil.

\section{MATERIALS AND METHOD}

\section{A. Materials}

\section{Polypropylene Fiber}

Geofibers are commercially available in different length and width. Synthetic polypropylene fibers were purchased from K-Fix Construction Chemicals, Chennai. It was mixed randomly with the soil to ensure complete dispersion and uniformity.

Table I shows various properties of fiber used in the experimental investigation. 
TABLE I PROPERTIES OF FIBER

\begin{tabular}{|l|c|}
\hline \multicolumn{1}{|c|}{ Properties } & Values \\
\hline Specific gravity & 0.91 \\
\hline Length of fiber (mm) & 12 \\
\hline Tensile strength (MPa) & 660 \\
\hline Modulus of Elasticity (GPa) & 4 \\
\hline Electrical Conductivity & Low \\
\hline Melting point $\left({ }^{0} \mathrm{C}\right)$ & 165 \\
\hline Water absorption & Negligible \\
\hline Acid and Alkali resistance & Excellent \\
\hline Fiber count & Approx. 14million $/ 0.45 \mathrm{~kg}$ \\
\hline
\end{tabular}

\section{Clay Soil}

The soil sample was collected from Government College of Technology campus, Coimbatore at a depth of $1.5 \mathrm{~m}$ from the ground level. The location has the longitude and latitude of are $76^{0} 93^{\prime} 62^{\prime} \mathrm{N}, 11^{0} 02^{\prime} 02^{\prime \prime} \mathrm{E}$ respectively. The laboratory studies were carried out as per IS 2720 and the properties are summarized in Table II.

TABLE II INDEX PROPERTIES OF CLAY SOIL

\begin{tabular}{|l|c|}
\hline \multicolumn{1}{|c|}{ Parameters } & Values \\
\hline Specific gravity & 2.67 \\
\hline Sand (\%) & 21.7 \\
\hline Silt (\%) & 8.7 \\
\hline Clay (\%) & 69.6 \\
\hline Liquid limit (\%) & 64.5 \\
\hline Plastic limit (\%) & 25 \\
\hline Plasticity index (\%) & 39.5 \\
\hline Shrinkage limit (\%) & 13.5 \\
\hline Free Swell Index (\%) & 79 \\
\hline IS Classification & $\mathrm{CH}$ \\
\hline Optimum moisture content (\%) & 18 \\
\hline Maximum dry density (g/cc) & 1.64 \\
\hline Cohesive strength Cu (kPa) & 153 \\
\hline
\end{tabular}

\section{B. Methodology}

\section{Test Procedure}

The Oedometer test was conducted as per IS: 2720 (Part 15) - 1986 [04], both on unreinforced and fiber reinforced soil sample of $20 \mathrm{~mm}$ thickness and $60 \mathrm{~mm}$ diameter. Both unreinforced and fiber reinforced soil samples were compacted by standard Proctor to attain the required dry unit weight $\left(16 \mathrm{kN} / \mathrm{m}^{3}\right)$ and optimum moisture content (18\%). The fiber percentage variation was selected as $0.1 \%$, $0.25 \%, 0.5 \%$, and $0.75 \%$ by dry weight of the soil. An aspect ratio (length /width) 12 is selected for the fiber. A seating pressure of $5 \mathrm{kPa}$ was applied to the specimen and allowed to form heave under fully saturated condition.

The seating pressure is maintained constant till equilibrium heave value is attained. The sample is then allowed to consolidate by applying pressure equal to two times the pressure used at the preceding stage. The pressures applied were $10 \mathrm{kPa}, 20 \mathrm{kPa}, 40 \mathrm{kPa}, 80 \mathrm{kPa}, 160 \mathrm{kPa}, 320 \mathrm{kPa}$. For each applied pressure, the sample is allowed to consolidate and the readings are observed for 24 hour at a time interval of $0,0.25,0.5,1,2,4,8,15,30,60 \mathrm{~min}$ and $2,4,8,24$ hour. Compression of specimen was continued till it attained the initial void ratio.

\section{RESULTS AND DISCUSSION}

\section{A. Effect of Fiber Reinforcement on the Rate of Heave Formation}

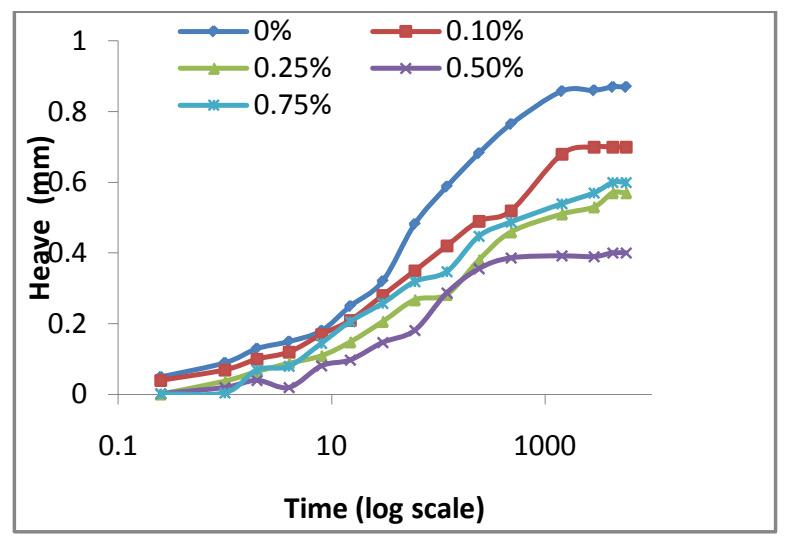

Fig. 1 Rate of Heave Formation

Fig. 1 shows the rate of heave formation on unreinforced and fiber reinforced soil specimen. It was observed that unreinforced soil attained its equilibrium heave value of $0.87 \mathrm{~mm}$ in 3days or 4380 min which was the highest heave value compared to that of the other reinforced soil specimen. The data showed that heave decreased on addition of fiber up to $0.5 \%$, but increased slightly when the percentage addition of fiber is increased to $0.75 \%$. For the fiber content of $0.5 \%$, swelling value was very less to about $0.4 \mathrm{~mm}$ in 2 days or $2880 \mathrm{~min}$. With the addition of fibers to soil there is reduction in heave and this is due to the interlocking effect of fiber [9].

Fiber occupies the spaces within the soil and holds them in place like the roots of the trees and, also due to the friction generated by polypropylene fiber. The heave observed from the experimental test were $0.87 \mathrm{~mm} 0.7 \mathrm{~mm}, 0.57 \mathrm{~mm}, 0.4 \mathrm{~mm}$ and $0.6 \mathrm{~mm}$ for $0 \%, 0.1 \%, 0.25 \%, 0.5 \%$ and $0.75 \%$ fiber respectively. It indicated that fiber reinforcement was effective in controlling heave.

\section{B. Effect of Fiber Reinforcement on Swell Potential and Swelling Pressure}

Swell potential is defined as the ratio of change in height to the original height. The effect of percentage addition of fiber on swell potential of clay soil is shown in Fig. 2. Swell 
potential decreased from $4.35 \%$ to $2 \%$ with the increase in percentage addition of fiber from $0 \%$ to $0.5 \%$. But the value of swell potential increases mildly when the percentage addition of fiber increased to $0.75 \%$.The values of swell potential for varying percentage of fibers are $4.35 \%$, $3.55 \%$, 2.85\%, $2 \%$, $3 \%$ respectively for $0 \%, 0.1 \%, 0.25 \%$, $0.5 \%, 0.75 \%$ fiber.

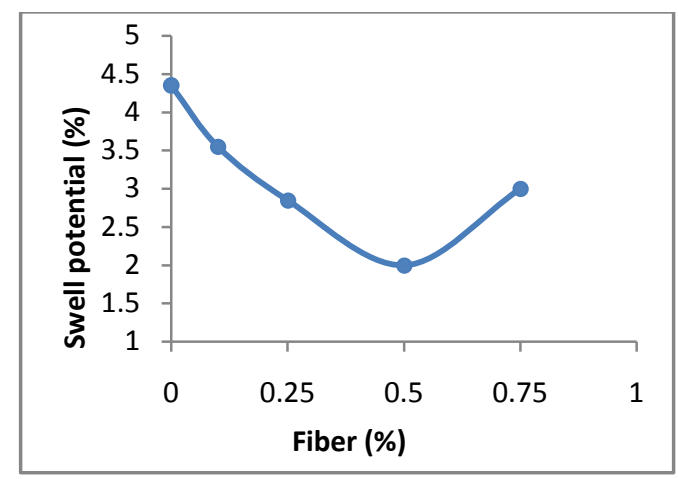

Fig. 2 Influence of fiber percentage on swell potential

Swelling pressure is defined as the pressure required to compress the fully swollen sample to its initial stage (initial void ratio or initial height) which is determined from the elogP curve shown in Fig. 3. As the specific gravity changes the initial void ratio before swelling was different for different specimens havings various fiber percentages.

Fig. 3 shows that addition of fiber decreases the swelling pressure of cohesive soil. The swelling pressure decreased with increase in the percentage addition of fiber up to $0.5 \%$ but it increases mildly when percentage addition increased to $0.75 \%$. The swelling pressure for unreinforced cohesive soil is observed as $72 \mathrm{kPa}$ and it was found that the values of swelling pressure reduced to $65 \mathrm{kPa}, 60 \mathrm{kPa}, 52 \mathrm{kPa}, 63 \mathrm{kPa}$ respectively at percentage addition of $0.1 \%, 0.25 \%, 0.5 \%$, $0.75 \%$ fiber.

As the maximum heave value decreased with introduction of fiber, the swelling pressure also reduced. The effect of percentage addition of fiber on swelling pressure of clay soil is shown in Fig. 4.

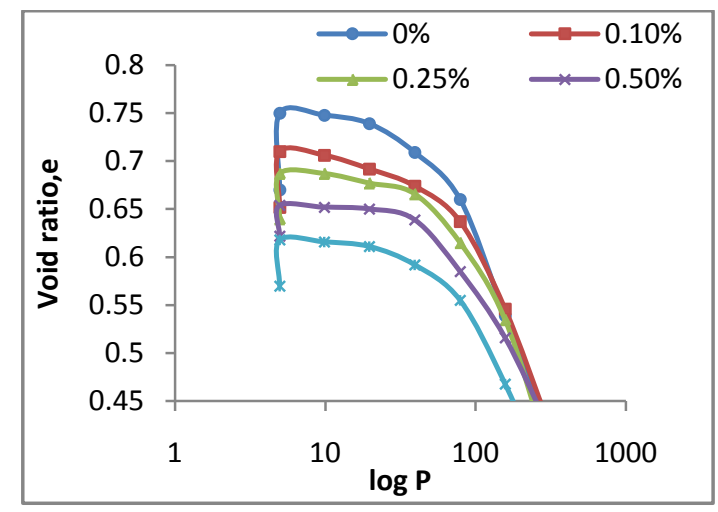

Fig. 3 e - $\log \mathrm{P}$ curve

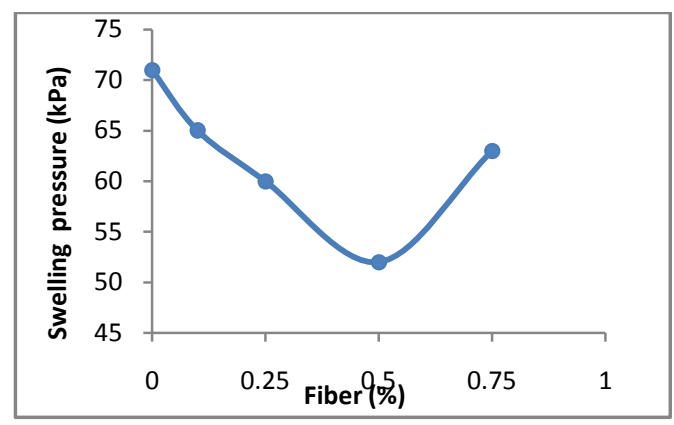

Fig. 4 Influence of fiber percentage on swelling pressure

The values of heave, swell potential and swelling pressure for varying percentage of fiber addition are shown in Table III.

TABLE III SWELLING PROPERTIES OF UNREINFORCED AND FIBER REINFORCED SOIL

\begin{tabular}{|c|c|c|c|c|}
\hline $\begin{array}{c}\text { Fiber } \\
\text { added } \\
(\%)\end{array}$ & $\begin{array}{c}\text { Heave } \\
\text { (mm) }\end{array}$ & $\begin{array}{c}\text { Time required } \\
\text { to achieve } \\
\text { equilibrium } \\
\text { heave(days) }\end{array}$ & $\begin{array}{c}\text { Swell } \\
\text { potential } \\
\mathbf{( \% )}\end{array}$ & $\begin{array}{c}\text { Swell } \\
\text { pressure } \\
\text { (kPa) }\end{array}$ \\
\hline 0 & 0.87 & 3 & 4.35 & 72 \\
\hline 0.1 & 0.7 & 3 & 3.55 & 65 \\
\hline 0.25 & 0.57 & 2 & 2.85 & 60 \\
\hline 0.5 & 0.4 & 2 & 2 & 52 \\
\hline 0.75 & 0.6 & 3 & 3 & 63 \\
\hline
\end{tabular}

\section{Consolidation Parameters}

The value of compression index $\left(C_{C}\right)$, Coefficient of compressibility $\left(a_{v}\right)$, and Coefficient of volume change $\left(m_{v}\right)$ are computed from the Fig.3 for reinforced and unreinforced soil. Compression index $\left(\mathrm{C}_{\mathrm{C}}\right)$, Coefficient of compressibility $\left(\mathrm{a}_{\mathrm{v}}\right)$, and Coefficient of volume change $\left(\mathrm{m}_{\mathrm{v}}\right)$ similar to swelling studies the optimum percentage of fiber is observed as $0.5 \%$. At $0.5 \%$ addition, there is decrease in the values of $\mathrm{c}_{\mathrm{c}}, \mathrm{a}_{\mathrm{v}}$ and $\mathrm{m}_{\mathrm{v}}$ are $0.22,0.8 \mathrm{~mm}^{2} / \mathrm{N}, 0.483 \mathrm{~mm}^{2} / \mathrm{N}$. The presence of fiber increases the resistance of soil against compression due to more fiber to fiber interaction. Fig.5-7 shows the effect of percentage addition of fiber on consolidation parameters such as $c_{c}, a_{v}, m_{v}$. Thus the consolidation parameters $c_{c}, a_{v}, m_{v}$ for both unreinforced and reinforced soil is presented in Table IV.

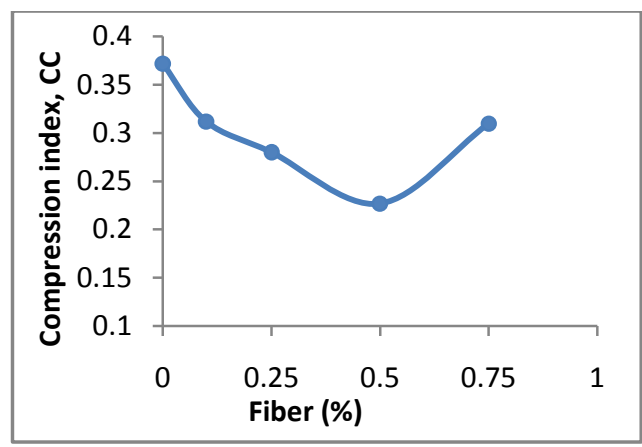

Fig. 5 Influence of fiber percentage on compression index $\left(\mathrm{C}_{\mathrm{C}}\right)$ 


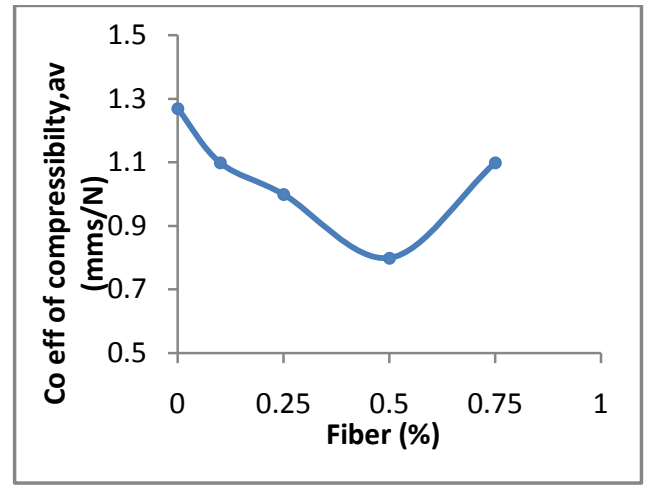

Fig. 6 Influence of fiber percentage on Co efficient of compressibility $\left(a_{v}\right)$

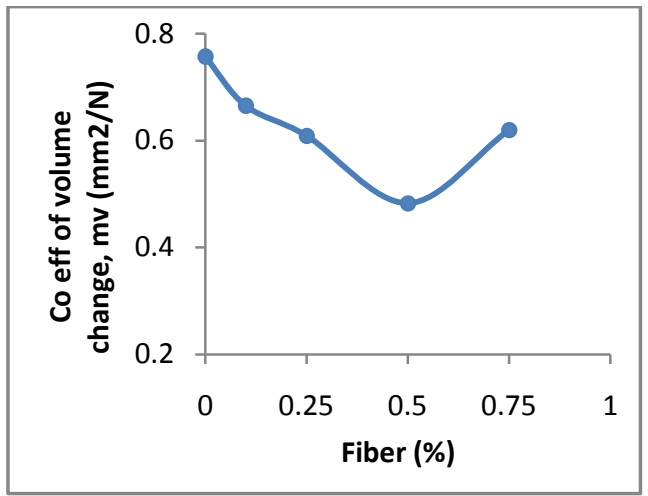

Fig. 7 Influence of fiber percentage on Co efficient of volume change $\left(m_{v}\right)$

TABLE IV CONSOLIDATION PARAMETERS OF UNREINFORCED AND FIBER REINFORCED SOIL

\begin{tabular}{|c|c|c|c|}
\hline $\begin{array}{l}\text { Fiber } \\
\text { added } \\
(\%)\end{array}$ & $\begin{array}{c}\text { Compression } \\
\text { Index }\left(C_{C}\right)\end{array}$ & $\begin{array}{c}\text { Coefficient of } \\
\text { Compressibility } \\
\left(a_{v}\right), \mathbf{m m}^{2} / \mathbf{N}\end{array}$ & $\begin{array}{c}\text { Coefficient of } \\
\text { Volume } \\
\text { change }\left(\mathrm{m}_{\mathrm{v}}\right), \\
\mathrm{mm}^{2} / \mathrm{N}\end{array}$ \\
\hline 0 & 0.372 & 1.27 & 0.757 \\
\hline 0.1 & 0.312 & 1.1 & 0.665 \\
\hline 0.25 & 0.28 & 1 & 0.609 \\
\hline 0.5 & 0.227 & 0.8 & 0.483 \\
\hline 0.75 & 0.31 & 1.1 & 0.620 \\
\hline
\end{tabular}

\section{IV.CONCLUSION}

Based on the results and discussion the following conclusions are drawn.

1. The heave decreased with inclusion of polypropylene fiber and the time required to achieve equilibrium heave value was very less compared to that of unreinforced soil specimen.
2. Swell potential decreased from $4.35 \%$ to $2 \%$ with increasing percentage addition of fiber from $0 \%$ to $0.5 \%$. For the same percentage addition of fiber the swelling pressure decreased to $52 \mathrm{kPa}$ compared to that of unreinforced soil which was about $72 \mathrm{kPa}$.

3. The compression index (Cc), coefficient of compressibility $\left(\mathrm{a}_{\mathrm{v}}\right)$, coefficient of volume change $\left(\mathrm{m}_{\mathrm{v}}\right)$ decreased with the addition of fiber in the soil. Though the above consolidation characteristics decreased with each percentage addition of fiber the percentage of improvement was significant for $0.5 \%$ fiber.

4. Therefore considering both swelling and consolidation characteristics, $0.5 \%$ addition of fiber yielded better results.

\section{REFERENCES}

[1] N. M. Al-Akhras, M. F. Attom, and A. I. H. Malkawi, "Influence of Fibers on Swelling Properties of Clayey Soil”, International Journal of Geosynthetics, ISSN: 1072-6349, Vol. 15, pp. 304-309, 2015.

[2] M. F. Attom, N. M. Al-Akhras and A. I. H. Malkawi, "Effect of Fibers on the Mechanical Property of Clayey Soil",Journal of Geotechnical Engineering, Vol. 162, pp. 277-282, 2009.

[3] Jian Li, Chaosheng Tang, Deying Wang, Xiangjun Pei and Bin Shi, "Effect of Discrete Fiber Reinforcement on Soil Tensile Strength", Journal of Rock Mechanics and Geotechnical Engineering, Vol. 6, pp. 133-137, 2014.

[4] IS: 2720 (Part 15) -1986, Determination of Consolidation Properties.

[5] M. H. Maher and D. H. Gray, "Static Response of Sands Reinforced with Randomly Distributed Fibers", Journal of Geotechnical Eng., ASCE,Vol. 116, No.11, pp. 1661-1677, 1990.

[6] Mahmood R. Abdi, Ali Parsapajouh and Mohammad A. Arjomand, "Effects of Random Fiber Inclusion on Consolidation, Hydraulic Conductivity, Swelling, Shrinkage Limit And Desiccation Cracking Of Clays”,International Journal of Civil Engineering, Vol. 6, No. 4, 2008.

[7] K. Mukherjeel, A. K. Mishra and Balaji A. Mudaliyar, "A review on Consolidation and Strength Behaviour of Fiber Reinforced Expansive Soil”, 50 th Indian Geotechnical Conference, 2015.

[8] Phanikumar, B. R. Amshu Malini andR. Karthika, "SwellConsolidation Characteristics of Artificial Sand Clay Mixes”, Indian Geotechnical Conference, IGS,Mumbai chapter \& IIT Bombay, 2010.

[9] B. R. Phanikumar and Ravideep Singla, "Swell-Consolidation Characteristics of Fibre-Reinforced Expansive Soil”, The Japanese Geotechnical Society, pp.0038-0806, 2016.

[10] Rabindra Kumar Kar, Pradip Kumar Pradhan and Ashutosh Naik, "Consolidation Characteristics of Fiber Reinforced Cohesive Soil”, International Journal of Scientific and Technology Research, Vol. 4, No. 06, ISSN 2277-8616, 2015,

[11] R. K. Kar and P. K. Pradan, "Strength and Comprssibilty Characteristics of Randomly Distributed Fiber Reinforced Soil”,International Journal of Geotechnical Engineering(IJGE), Vol. 5, No. 2, pp. 235-243, April 2011.

[12] Tung-Wen Hsu and Shuan-Chai Lu, "Behavior of One-dimensional Consolidation", Journal of Engineering Mechanics, ASCE,Vol. 457, 2006.

[13] B. V. S. Viswanadham, B. R. Phanikumar Rahul andV. Mukherjee,"Swelling behaviour of a Geofiber-Reinforced Expansive Soil”,Geotextiles and Geomembranes, Vol.27, pp. 73-76. 2009.

[14] Yi Cai, Bin Shi, W.W.Charles and Chao-sheng Tang, "Effect of Polypropylene Fibre and Lime Admixture on Engineering Properties of Clayey Soil”, Engineering Geology, Vol. 87, pp. 230-240, 2006. 